\title{
Brain ischemia and ischemic blood-brain barrier as etiological factors in sporadic Alzheimer's disease
}

\author{
Ryszard Pluta \\ Marzena Ułamek \\ Laboratory of Ischemic \\ and Neurodegenerative Brain \\ Research, Department \\ of Neurodegenerative Disorders, \\ Medical Research Centre, Polish \\ Academy of Sciences, Warsaw, Poland
}

\begin{abstract}
The development of neuronal death and amyloid plaques is a characteristic feature of ischemic- and Alzheimer-type dementia. An important aspect of neuronal loss and amyloid plaques are their topography and neuropathogenesis. This review was performed to present the hypothesis that different fragments of blood-borne amyloid precursor protein are able to enter the ischemic blood-brain barrier. Chronic disruption of the blood-brain barrier after ischemic injury was shown. As an effect of chronic ischemic blood-brain barrier injury, a visible connection of amyloid plaques with neurovasculature was observed. This neuropathology appears to have similar distribution and mechanisms to Alzheimer's disease. The usefulness of rival ischemic theory in elucidating the neuropathogenesis of amyloid plaques formation and neuronal death in Alzheimer's disorder is discussed.
\end{abstract}

Keywords: brain ischemia, ischemic blood-brain barrier, neuronal death, amyloid plaques, platelets, leukocytes, dementia, Alzheimer's disease

\section{Introduction}

Two forms (genetic and sporadic) of Alzheimer's disease involve main common events: neuronal damage and amyloid plaques accumulation in the human brain. Neuronal changes in the end-stage patient brain are diffuse and widespread and neuropathological autopsy findings include significant neuron death. Moreover Alzheimer's disease is characterized by a progressive dementia. An interesting suggestion about this phenomenon is that neuronal cells, which are involved with learning and memory, may synthesize specific substances associated with these cognitive activities and that dysfunction of the blood-brain barrier (Sohrabji 2007; Zipser et al 2007) may cause selective loss of these specific cells (Arshavsky 2006). The extracellular space in brain is infiltrated by blood borne $\beta$-amyloid peptide $1-42$, a neurotoxic peptide that interferes with the cells' vital mechanisms and ultimately kills them (Atwood et al 2003a; Swerdlow 2007). This additional supporting evidence for blood-brain barrier disruption in Alzheimer's disease, which is related to the accumulation of $\beta$-amyloid peptide; the featured lesion of the disorder (Pluta et al 1996). The brain vessels show signs of vessel inflammation and amyloid depositions. Another set of evidence suggests that Alzheimer's disease may have an autoimmune root, where especially neuronal cells are targeted after opening blood-brain barrier (D'Andrea 2005). The first description of the neuropathology in the patient brain suffering from Alzheimer's disease by Alzheimer in 1907 presented cerebrovascular alterations of endothelium especially in small vessels (blood-brain barrier vessels) (Kalaria 1999, 2002; Grammas 2000; Humpel and Marksteiner 2005; Dede et al 2007) that have not received much attention (Pluta 2000). The onset of Alzheimer's disease is unknown and symptoms develop slowly during patient life. In the end stage of this disorder, 
patients are totally dependent on caregivers and other diseases may lead them to death.

The etiology and important risk factors for Alzheimer's disease are not well known (Spires and Hyman 2005; Pluta 2006a). It is believed that major causes for this disorder include diseases of old age such as transient focal and complete brain ischemic (Kalaria 2000; Pluta 2006a) and head (Nimmo et al 2004) injuries. Single and most probably multiple brain ischemic injuries can develop changes similar to those observed in Alzheimer's disease (Pluta 2006a).

Some investigators have presented the hypothesis that the primary event in the onset of Alzheimer's disease is ischemic injury of brain (Kalaria 2000; Pluta 2004b, 2006a). According to this rival theory the blood-brain barrier vessels are damaged (Kalaria 1999; Dede et al 2007) and at the same time cause the neurotoxic $\beta$-amyloid peptide to be released from circulatory system into brain parenchyma (Pluta et al 1996) and subsequently react with ischemic neurons (Koistinaho et al 2002) as secondary cause of neuronal death (Figure 1).

The precursor protein for $\beta$-amyloid peptide can exist as both a membrane cell surface receptor and a soluble form, mostly in circulating blood. Blood platelets carry large amounts of $\beta$-amyloid peptide and its precursor (Chen et al 1995). The prolonged opening of ischemic blood-brain barrier to $\beta$-amyloid peptide (Pluta 2003, 2005; Pluta et al 2006) and exposure to the potentially neurotoxic peptide probably initiates amyloid plaques formation/maturation (Kawai et al 1990; Dickstein et al 2006) with further additional neuronal cell death (Koistinaho et al 2002) and massive neuronal network destruction (Iwasaki et al 2006).

According to the ischemic theory of Alzheimer's disease, neuronal cells are first damaged and then the blood-brain barrier vessels are impaired, which causes the neurotoxic $\beta$-amyloid peptide to be released from blood and subsequently infiltrate the neuronal cells and brain parenchyma (Pluta 2004a, 2004b, 2006a, 2006b, 2007a, 2007b). As a late effect, there will be a narrowing of the small vessels lumen leading to secondary ischemic brain episodes as a vicious cycle (Pluta 2006b, 2007b) in which the neuronal network will be completely impaired.

In this review we present data that supports the role of ischemia in neuronal death and ischemic blood-brain barrier in amyloid plaques development in Alzheimer's disease etiology.

\section{Influence of ischemia and $\beta$-amyloid peptide on brain cells}

In the ischemic brain, the main neuropathological focus is concentrated on structural changes in hippocampus because this part of the brain is selectively vulnerable to ischemic- and Alzheimer-type injury. In some cases, complete disappearance of vulnerable pyramidal neurons in the CA1 area was noted 7 days after ischemia (Butler et al 2002). Moreover, one third of cases with experimental brain ischemia did not present full disappearance of pyramidal cells in CA1 region during short-term survival (Sadowski et al 1999; Pluta 2000). These animals developed complete death of all neurons of CA1 sector in late stages (Pluta 2000, 2002a, 2002b). Some studies presented marked structural changes in neurons considered to be resistant to ischemia such as: in sector CA2, CA3, and CA4 of hippocampus and dentate gyrus (Pluta 2000). These areas presented acute ischemic changes in neurons from 1 to 12 months following ischemic injury (Pluta 2000). Recently was found that pathological structural processes in ischemic neurons continue well beyond the acute stages of insult (Pluta 2000, 2002a). In these situations, enduring ischemic blood-brain barrier dysfunction (Pluta 2006 b, 2007b) probably leads to enhanced ischemic neuronal vulnerability to $\beta$-amyloid peptide (Figure 1) (Table 1) (Koistinaho et al 2002).

Some studies show that astrocytic apoptosis may contribute to the pathogenesis of different disorders such as ischemic brain and Alzheimer's disease (Takuma et al 2004; Pluta 2006a). Astrocytic reactions that are noted in the ischemic brain and Alzheimer's disease are swelling, astrogliosis, and astrocytosis (Bernaudin et al 1998; Stoltzner et al 2000). In brain ischemia, some experimental studies noted the early import of different epitopes of amyloid precursor protein from brain parenchyma and circulatory system to the astrocytes and in the late stages the export of the neurotoxic C-terminal of amyloid precursor protein and $\beta$-amyloid peptide from dead astrocytes to the brain tissue (Table 1) (Pluta et al 1994b; Pluta 2002b, 2004a, 2004b).

At early stages of brain ischemia and reperfusion, the N-terminal of amyloid precursor protein (Pluta et al 1994b) may be synthesized by cells derived from the vascular endothelium that became fragmented after injury (Badan et al 2004). This idea is supported by the expression and production of $\beta$-secretase in ischemic brain (Wen et al 2004; Sun et al 2006; Zhang et al 2007). Furthermore presenilin expressed in ischemic brain (Tanimukai et al 1998; Pennypacker et al 1999; Pluta 2001) is involved in the metabolism of amyloid precursor protein to produce $\beta$-amyloid peptide through the $\gamma$-secretase complex (Wolfe et al 1999). These secretases are involved in amyloidogenic metabolism of amyloid precursor protein. At first, amyloid precursor protein is cleaved at the $\mathrm{N}$-terminal of the $\beta$-amyloid peptide domain by 


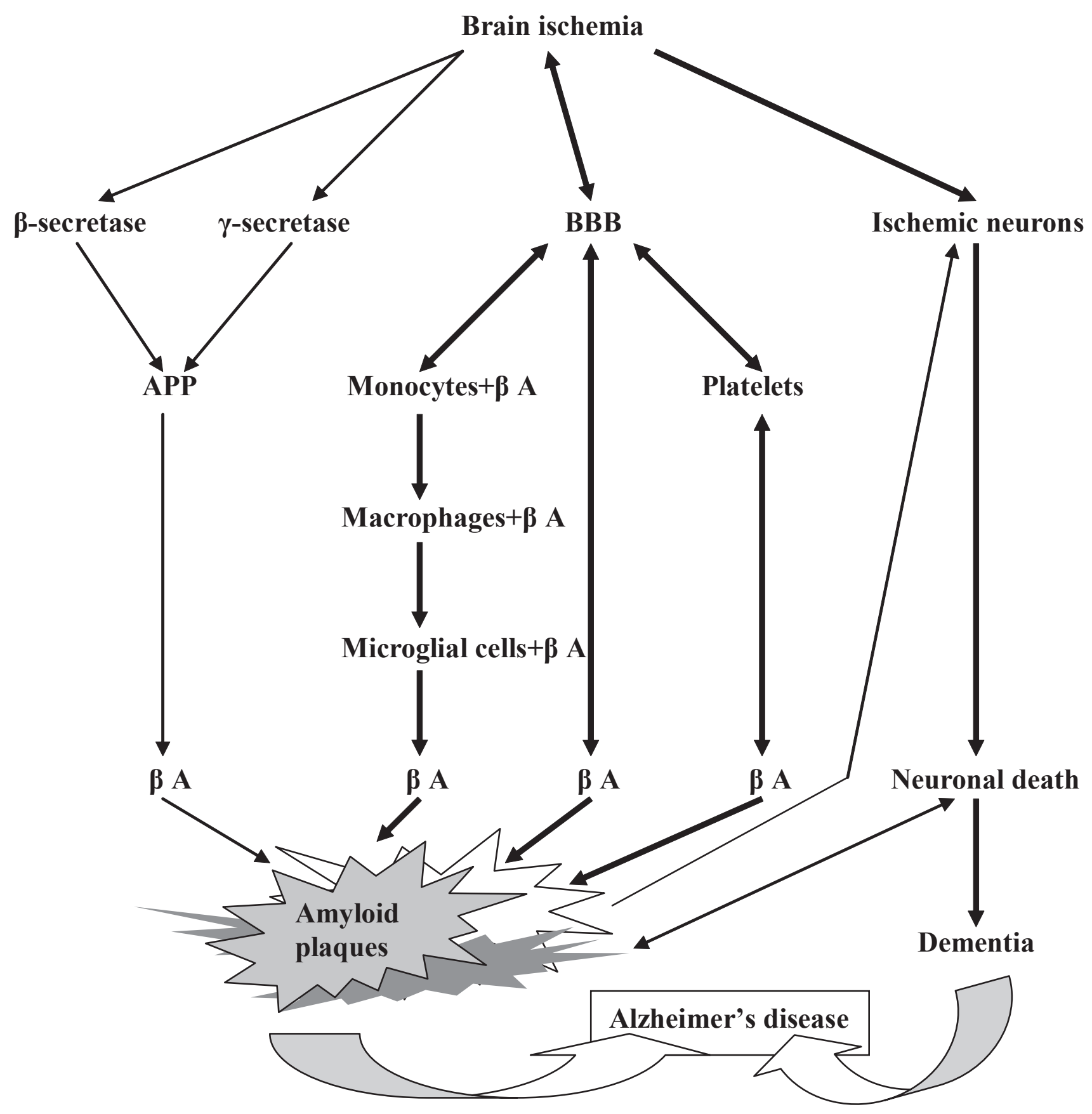

Figure I Schematic diagram of the main ischemic pathological processes in sporadic Alzheimer's disease. Abbreviations: APP, amyloid precursor protein; $\beta \mathrm{A}, \beta$-amyloid peptide; $\mathrm{BBB}$, blood-brain barrier. 
Table I Ischemia and $\beta$-amyloid peptide and brain cells

\begin{tabular}{lll}
\hline Cells & Influence & References \\
\hline Neurons & ++ & Pluta et al 1994b, 1997b; Abramov et al 2003; Badan et al 2004; Pluta 2006a \\
Astrocytes & ++ & Banati et al 1995; Palacios et al 1995; Pluta et al 1996, 1997b, 1999; Pluta 2000, \\
& & 2002a, 2002b, 2006a; Nihashi et al 200I; Matsunaga et al 2003; Wyss-Coray et al \\
& ++ & 2003; Koistinaho et al 2004; Takamura et al 2004 \\
Oligodendrocytes & + & Irving et al 1997; Pluta et al 1997b; D'Andrea et al 2004 \\
Microglial cells & Banati et al 1995; Badan et al 2004; Malm et al 2005; Pluta 2006a; Simard et al 2006 \\
Ependymal cells & ++ & Pluta et al 1996, 1997a, I997b \\
Endothelial cells & ++ & Pluta et al 1996, 1997a, I997b; Thomas et al 1996; Badan et al 2004 \\
Pericytes & ++ & Pluta et al 1996; Lupo et al 200I; Anfuso et al 2004
\end{tabular}

Notes: Influence, +++ - strong; ++ - moderate; +- weak.

protease called $\beta$-secretase. In the second step, the product of $\beta$-secretase is cleaved by $\gamma$-secretase to form free soluble $\beta$-amyloid peptide. Endothelial cells change shape and size over time to become incorporated into the amyloid plaques in a close spatial relationship with damaged or dead astrocytes. The same study shows that C-terminal of amyloid precursor protein accumulates in neurons after focal ischemia and as the infarct progresses, the $\mathrm{C}$-terminal of amyloid precursor protein immunoreactive elements become increasingly larger in the core even though the neurons are dying and the core becomes largely acellular (Badan et al 2004). The same and other studies suggest that $\mathrm{C}$-terminal of amyloid precursor protein and $\beta$-amyloid peptide noted in microglia could be due to the phagocytosis of dead neurons remnants containing $\mathrm{C}$-terminal of amyloid precursor protein and $\beta$-amyloid peptide by microglia (Figure 1) (Table 1) (Badan et al 2004; D'Andrea et al 2004). Moreover there are reports showing that astrocytes but not microglial cells can take up $\beta$-amyloid peptide (Table 1) (Matsunaga et al 2003; Wyss-Coray et al 2003; Pluta 2006a). Other work shows that C-terminal of amyloid precursor protein induces the death of astrocytes whereas the loss of neurons is a secondary consequence of the neuronal dependence on astrocytes for antineurotoxic $\beta$-amyloid peptide protection (Figure 1) (Table 1) (Abramov et al 2003; Pluta 2006a). The localization of some fragments of amyloid precursor protein in astrocytes may be of significant relevance to Alzheimer's disease in which chronic astrocytosis is thought to play a key role in the evolution of amyloid plaques.

\section{Ischemic blood-brain barrier permeability}

Brain ischemia mediated a number of vessel events which are open blood-brain barrier and tight junctions, diffuse leakage across necrotic vessel walls, and vasoconstriction (Petito et al 1982; Mossakowski et al 1993, 1994; Pluta et al 1994a, 2006; Wisniewski et al 1995; Gartshore et al 1997; Shinnou et al 1998; Lippoldt et al 2000; Ueno et al 2002; Pluta 2003, 2005).

Until one year following brain ischemia-reperfusion injury brain gray and white matter areas contained single isolated and scattered sites of horseradish peroxidase extravasations (Table 2) (Mossakowski et al 1994; Pluta et al 1994a, 2006; Pluta 2003, 2005). Microscopic studies of different ischemic brain sections revealed diffuse and focal staining of tracer. Penetrating vessels across different brain structures displayed horseradish peroxidase immunoreactivity in walls. In hippocampus, cortex, basal ganglia, and thalamus and cerebellum, the above horseradish peroxidase leakage was noted. In summary, ischemic brains presented chronic and random blood-brain barrier changes. Horseradish peroxidase permeability involved arterioles, capillaries, venules, and veins.

After short-term survival (7 days) following brain ischemia, experimental animals presented with gray and white matter perivascular immunoreactivity for all epitopes of amyloid precursor protein (Table 2) (Pluta et al 1994b). On the contrary, following long-term survival of animals, staining only for the toxic $\mathrm{C}$-terminal of amyloid precursor protein and to the $\beta$-amyloid peptide was observed (Pluta et al 1997b; Pluta 2000, 2003, 2005). Multiple and abundant C-terminal of amyloid precursor protein and $\beta$-amyloid peptide staining deposits embraced and/or adjoined the capillaries. The deposits size was different and irregular in shape. Diffuse deposits of C-terminal of amyloid precursor protein and $\beta$-amyloid peptide like "puff of smoke" were also observed. Capillaries lumens and their inner and outer side of walls were also stained. Immunoreactivity inside capillaries with 
Table 2 Ischemic blood-brain barrier permeability

\begin{tabular}{|c|c|c|}
\hline Permeability & Intensity & References \\
\hline HRP & $\leftrightarrow$ & $\begin{array}{l}\text { Petito et al 1982; Pluta et al 1994a, 2006; Gartshore et al 1997; Shinnou et al 1998; } \\
\text { Ueno et al 2002; Pluta 2003, 2005; Gidday et al } 2005\end{array}$ \\
\hline NAPP & $\downarrow$ & Pluta et al I994b; Badan et al 2004; Pluta 2005 \\
\hline$\beta A$ & $\uparrow$ & $\begin{array}{l}\text { Pluta et al 1994b, 2006; Jendroska et al 1995; Ishimaru et al 1996; Wisniewski } \\
\text { and Maslinska 1996; Pluta 2003, 2005; Van Groen et al } 2005\end{array}$ \\
\hline CAPP & $\uparrow$ & Pluta et al 1994b, 2006; Pluta 2003, 2005; Badan et al 2004 \\
\hline$\beta A I-42$ & $\uparrow$ & Pluta et al 1996, 1997a, 1999, 2000 \\
\hline Apo $E$ & $\uparrow$ & Kida et al 1995; Ishimaru et al 1996; Pluta 2000 \\
\hline Apo Al & $\uparrow$ & Kida et al 1995; Pluta 2000 \\
\hline Apo J & $\uparrow$ & Kida et al 1995; Pluta 2000 \\
\hline Platelets & $\uparrow$ & Pluta et al I994c; Ishikawa et al 2004; Ritter et al 2005 \\
\hline Leukocytes & $\uparrow$ & Caceres et al 1995; Farkas et al 2003; Ishikawa et al 2004; Ritter et al 2005; Pluta 2006a \\
\hline
\end{tabular}

Notes: Intensity, $\leftrightarrow$ permanent; $\uparrow$ increasing; $\downarrow$ decreasing.

Abbreviations: HRP, horseradish peroxidase; NAPP, N-terminal of amyloid precursor protein; $\beta A, \beta$-amyloid peptide; CAPP, C-terminal of amyloid precursor protein; $\beta A I-42$, human $\beta$-amyloid peptide I-42; Apo E, apolipoprotein E; Apo AI, apolipoprotein AI; Apo J, apolipoprotein J.

a halo of C-terminal of amyloid precursor protein staining in the surrounding parenchyma (Pluta 2005) suggested diffusion of C-terminal of amyloid precursor and $\beta$-amyloid peptide out of the vascular compartment (Table 2). In any case, the halo of $\beta$-amyloid peptide staining in the perivascular space suggests that $\beta$-amyloid peptide can easy cross small vessel walls. These deposits were noted mainly in the hippocampus, brain, and entorhinal cortex.

The above suggestions are supported by intravenous injection of human $\beta$-amyloid peptide 1-42 into ischemic animals, which accumulated this peptide in the ischemic brain gray and white matter vessels walls and in perivascular space (Table 2) (Pluta et al 1996, 1997a, 1999). $\beta$-amyloid peptide 1-42 can be transported by the blood-brain barrier receptormediated transport (Deane et al 2003) and by blood-brain barrier permeability caused by ischemic injury (Pluta et al $1996,1997 \mathrm{a}, 1999,2000$ ) or $\beta$-amyloid neurotoxicity on ischemic blood-brain barrier structure (Table 1) (Thomas et al 1996; Fiala et al 1998; Farkas et al 2003; Paris et al 2004a, 2004b).

The abnormal staining for apolipoproteins $\mathrm{E}, \mathrm{A} 1$, and $\mathrm{J}$ was noted perivascularly (Table 2) (Kida et al 1995; Pluta 2000). Apolipoprotein perivascular deposits were well delineated and irregular and with contact with ischemic blood-brain barrier vessels. Diffuse, broad, but faint areas were also seen. Extracellular apolipoproteins $\mathrm{E}$ and $\mathrm{J}$ deposits were heavily labeled by antibody to apolipoprotein A1, stronger than by apolipoprotein E antibody (Kida et al 1995). They were stained stronger by antibody to apolipoprotein E than apolipoprotein J (Kida et al 1995). It is of interest to notice that perivascular deposits of apolipoproteins colocalize with deposits of different fragments of amyloid precursor protein (Kida et al 1995). Apolipoprotein E can modulate and promote the aggregation of soluble $\beta$-amyloid peptide into the fibrillar conformation. Apolipoprotein J is implicated in transport of $\beta$-amyloid peptide across the blood-brain barrier. The main role of apolipoproteins $\mathrm{E}, \mathrm{A} 1$, and $\mathrm{J}$ in controlling the levels of soluble $\beta$-amyloid peptide in the extracellular/perivascular space of brain as well as their influence on amyloid plaques formation is suggested. These data demonstrate additive effects of apolipoproteins on influencing $\beta$-amyloid peptide deposition around blood vessels and that they play an important role in regulating extracellular brain $\beta$-amyloid peptide metabolism independent of $\beta$-amyloid peptide synthesis. Another function, especially for apolipoprotein $\mathrm{E}$ in brain, is the suggested clearance of ischemic tissue probably by reverse transport of remnants into blood (Pluta et al 2000). Delayed clearance may hamper healing and reconstruction of the ischemic blood-brain barrier. These observations indicate that perivascular apolipoproteins $\mathrm{E}, \mathrm{A} 1$, and $\mathrm{J}$ accumulation after ischemia may represent a secondary injury factor that could exacerbate healing of ischemic brain.

In different times following ischemic brain injury platelets occurring in aggregates were noted to adhere to the endothelium lining of ischemic blood-brain barrier vessels (Pluta et al 1994c; Pluta 2003, 2005). Ischemic platelets contained pseudopodia, which made strong contact with the endothelium. As an effect of these alterations the "no-reflow phenomenon" was noted (Mossakowski et al 1993; Pluta et al 
1994c; Pluta 2003). Moreover, platelets were observed on the abluminal side of vessels (Table 2) (Pluta et al 1994c; Pluta 2003, 2005). These kind of changes occurred in arterioles, capillaries, venules, and veins independently of survival time following brain ischemia. Some data suggest that ischemic brain injury results in an increase number of platelet-leukocytes complexes (Ishikawa et al 2004) in the circulatory system (Ritter et al 2005). Another study presented increased platelet-leukocyte-endothelium interactions after local brain ischemia (Ishikawa et al 2004). A growing body of evidence has suggested that white cells can play an important pathological role in ischemic brain (Caceres et al 1995; Gidday et al 2005). Matrix metalloproteinase-9 from white cells recruited to the ischemic brain tissue promotes further white cell recruitment (Table 2) to the same brain areas in a positive feedback manner and causes secondary blood-brain barrier breakdown to a primary ischemic episode (Gidday et al 2005). Microscopic investigation of ischemically damaged blood-brain barrier vessels identified leukocytes adhering to the endothelium of capillaries and venules (Caceres et al 1995). This phenomenon is probably important in transendothelial leukocytes passage (Table 2). Endothelial changes and white cells accumulation and adherence also reflect a "no-reflow phenomenon."

\section{Influence of $\beta$-amyloid peptide on ischemic blood-brain barrier}

Studies of ischemic microvessels from brain presented vasospasm during recirculation time (Wisniewski et al 1995; Ohtake et al 2004). The pathological hallmarks of vasospasm included undulations of basement membrane and endothelium with an increased number of endothelial microvilli (Pluta et al 1991). Some damaged endothelial cells presented rupture of endothelium membranes (Caceres et al 1995). Other studies of ischemic endothelium included an increased number of deep crater-like pits, endothelium microvilli, and enlarged junctional ridging (Pluta et al 1991). As an effect of presented pathology, aggregating platelets developed microthrombi attached to the vessel wall, which caused a continuous supply of constrictors such as $\beta$-amyloid peptide (Chen et al 1995; Thomas et al 1996). Current results suggest that platelets are the main ischemic cause in reperfusion injury, not only through aggregation and thrombus formation, but also through involvement in inflammation processes with leukocytes (Nishijima et al 2004). Due to the fact that soluble $\beta$-amyloid peptide causes vascular constriction (Thomas et al 1996; Niwa et al 2001) and endothelial cell injury (Table 1) (Thomas et al 1996), a role for soluble $\beta$-amyloid peptide in vasospasm and blood-brain barrier changes has been suggested. During recirculation following ischemic brain injury, islets of necrotic endothelium in capillaries was found (Petito et al 1982; Mossakowski et al 1994; Pluta et al 1994a). Necrotic blood-brain barrier vessels characterize diffuse leakage of different blood elements (Petito et al 1982; Mossakowski et al 1994; Pluta et al 1994a). This phenomenon is probably due to senescent endothelium, which is triggered during reperfusion and is accelerated by $\beta$-amyloid peptide (Mossakowski et al 1994). Senescent endothelial cells are a common hallmark of vessel aging (Erusalimsky and Kurz 2005) and are probably also accelerated by ischemic insults (Mossakowski et al 1994). Another problem during recirculation, senescent endothelial cells are covered with $\beta$-amyloid peptide ischemic vessel walls where $\beta$-amyloid peptide acts as antiangiogenic factor (Paris et al 2004a, 2004b). Ischemic episodes and $\beta$-amyloid peptide harmful influence on pericytes (Table 1) (Lupo et al 2001; Anfuso et al 2004) and astrocytes (Table 1) can regulate blood-brain barrier vessel angiogenesis and can disrupt the normal blood-brain barrier function (Ramsauer et al 2002).

\section{Guarding ischemic brain by estrogens}

The incidence of Alzheimer's disease cases is genderrelated (Pluta 2006a) and the risk of Alzheimer's disease in women is significantly greater than in men. The cumulative risk for Alzheimer's disease in women is greater because of a lack of estrogen (Figure 2) after menopause, which has been proposed as a risk factor for Alzheimer's disease among women (Pluta 2006a). Estrogen effects have been presented as blood-brain barrier function control through intercellular junction proteins (Kang et al 2006) and/or intracellular transport elements and through protective effects on the cellular components of barrier such as endothelial, pericytes, and astrocytes cells (Yang et al 2005), cells which are vulnerable to aging and ischemia (Table 1) influence in the context of normal blood-brain barrier activity (Figure 2) (Sohrabji 2007; Zipser et al 2007). Pathological permeability of the blood-brain barrier can expose brain parenchyma to different elements of blood (Table 2) that directly and/or indirectly harm neuronal cells (Table 1) and potentate other neuropathological processes. Age-related cascades in different areas of the brain can have far reaching consequences for cognitive ability and affect. Most investigators have taken the approach of studying estrogen influence on neuropathological events related to 


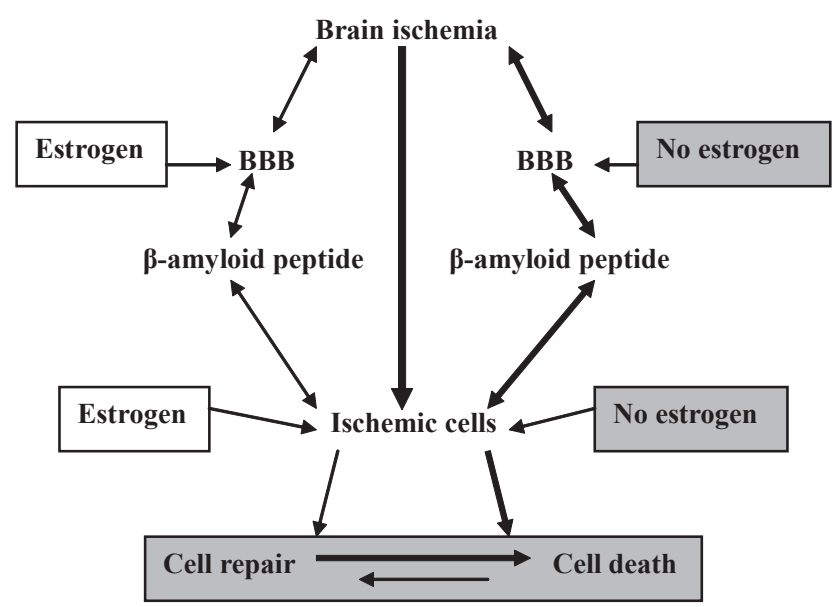

Figure 2 Role of estrogen in ischemic $\beta$-amyloid peptide neuropathology and ischemic brain cells injury.

Abbreviation: BBB, blood-brain barrier.

Alzheimer's disease (Figure 2) (Simpkins et al 1997; Dubal et al 1998; Shi et al 1998; Chi et al 2002, 2005). Estrogens exert neuroprotective activity in experimental models of brain ischemia (Figure 2) (Simpkins et al 1997; Dubal et al 1998; Shi et al 1998; Chen et al 2001; Chi et al 2002; Yang et al 2005), but the precise mechanism of their protection is not clearly understood. These hormones may preserve neuronal health (Chen et al 2001) by maintaining the integrity of the blood-brain barrier (Figure 2) (Chi et al 2002, 2005). Another possibility is that estrogen attenuates overexpression of amyloid precursor protein messenger RNA (Shi et al 1998). The protective effects of estrogens are seen in all of the neurovascular unit components including vascular endothelial cells, astrocytes, microglia, and neurons (Chen et al 2001; Yang et al 2005). Additionally postischemic estrogens reduce hypoperfusion and secondary ischemic episodes following brain ischemia (McCullough et al 2001). Prevention of brain ischemia and treatment ischemic episodes may have significant implications for Alzheimer's disease therapy. In view of the earlier observations that cognitive decline is progressing after brain ischemia, there is the distinct possibility that we can prevent this decline by targeting the slowly progressing pathology that follows ischemic injury by aiming at molecular events now shown to change following brain ischemia.

\section{Conclusion}

$\beta$-amyloid peptide is the main element of the fibrils in senile plaques in the Alzheimer's disease brain. A soluble form of $\beta$-amyloid peptide has been found in plasma
(Mehta and Pirttila 2002). A main vascular source for both the amyloid precursor protein and soluble $\beta$-amyloid peptide are in blood platelets. There is a growing body of evidence indicating that $>90 \%$ of soluble $\beta$-amyloid peptide found in the circulatory system is stored in platelets body (Chen et al 1995). Acute and chronic ischemic neuronal death and ischemic neurons with enduring blood-brain barrier leakage (Pluta 2003, 2005; Pluta et al 2006) and platelets in the blood-brain barrier vessels' perivascular space (Table 2) (Pluta et al 1994c; Pluta 2003) with neurotoxic epitopes of amyloid precursor protein deposition are involved in the gradual maturation of injurious process in ischemic gray and white matter (Table 1), which lead to progressive dementia and Alzheimer's disease (Pluta 2007c).

We propose the role for brain ischemic injury as an alternative etiology/hypothesis of Alzheimer's disease that triggers repetitive microischemic insults which form the basis for development of main neuropathological processes in Alzheimer's disease (Pluta 2007c). The profile of neuronal and blood-brain barrier pathology noted in ischemic brain shares a commonality with the same alterations in Alzheimer's disease. Ischemic neuronal changes have been implicated in the pathogenesis of dementia and ischemic blood-brain barrier changes are involved in amyloid plaques formation (Ujiie et al 2003). In Alzheimer's disease, the decreased length of cerebral capillaries correlates well with neuropathology and clinical features of dementia (Attems and Jellinger 2004; Bailey et al 2004). Islets of regressed, senescent (Minamino et al 2004) and degenerated ischemically blood-brain barrier vessels (Petito et al 1982; Mossakowski et al 1994; Pluta et al 1994a) probably act as seeds-core for the amyloid plaques. Thus, this data support theory that chronic ischemic blood-brain barrier permeability can cause angiopathy, vascular senescence (Minamino et al 2004), neuroinflammatory response (Nimmo et al 2004), and amyloid plaques, which also occur in the Alzheimer's disease brain.

The dysfunction of ischemic blood-brain barrier vessels with insufficient repair (Atwood et al 2003b; Dickstein et al 2006), vascular regression, and senescence, and aberrant and insufficient angiogenesis represent new pathogenic mechanism(s) involved in maturation of Alzheimer's disease and final development of amyloid plaques which are unrelated to primary ischemic neuronal death (Ishimaru et al 1996; Van Groen et al 2005).

\section{Acknowledgments}

This work was supported in part by the Medical Research Centre, the Polish Ministry of Science and High Education 
(2007-2010-Cost/253/2006) and the European Union (Cost Action B-30). The authors report no conflicts of interest in this work.

\section{References}

Abramov AY, Canevari L, Duchen MR. 2003. Changes in intracellular calcium and glutathione in astrocytes as the primary mechanism of amyloid neurotoxicity. $J$ Neurosci, 23:5088-95.

Alzheimer A. 1907. [Über eine eigenartige Erkrankung der Hirnrinde.] Allg Z Psychiatr Psych Gericht Med (Berlin), 64:146-8.

Anfuso CD, Assero G, Lupo G, et al. 2004. Amyloid beta (1-42) and its beta (25-35) fragment induce activation and membrane translocation of cytosolic phospholipase A (2) in bovine retina capillary pericytes. Biochem Biophys Acta, 1686:125-38.

Arshavsky YL. 2006. Alzheimer's disease, brain immune privilege and memory: A hypothesis. J Neural Transm, 113:1697-707.

Attems J, Jellinger KA. 2004. Only cerebral capillary amyloid angiopathy correlates with Alzheimer pathology - a pilot study. Acta Neuropathol, 107:83-90.

Atwood CS, Obrenovich ME, Liu T, et al. 2003a. Amyloid-beta: a chameleon walking in two worlds: a review of the trophic and toxic properties of amyloid- $\beta$. Brain Res Brain Res Rev, 43:1-16.

Atwood CS, Bowen RL, Smith MA, et al. 2003b. Cerebrovascular requirement for sealant, anti-coagulant and remodeling molecules that allow for the maintenance of vascular integrity and blood supply. Brain Res Brain Res Rev, 43:164-78.

Badan I, Dinca I, Buchhold B, et al. 2004. Accelerated accumulation of N- and C-terminal beta APP fragments and delayed recovery of microtubule-associated protein $1 \mathrm{~B}$ expression following stroke in aged rats. Eur J Neurosci, 19:2270-80.

Bailey TL, Rivara CB, Rocher AB, et al. 2004. The nature and effects of cortical microvascular pathology in aging and Alzheimer's disease. Neurol Res, 26:573-8.

Banati RB, Gehrmann J, Wießner C, et al. 1995. Glial expression of the $\beta$-amyloid precursor protein (APP) in global ischemia. J Cereb Blood Flow Metab, 15:647-54.

Bernaudin M, Nouvelot A, MacKensie ET, et al. 1998. Selective neuronal vulnerability and specific glial reactions in hippocampal and neocortical organotypic cultures submitted to ischemia. Exp Neurol, 150:30-9.

Butler TL, Kassed CA, Sanberg PR, et al. 2002. Neurodegeneration in the rat hippocampus and striatum after middle cerebral artery occlusion. Brain Res, 929:252-60.

Caceres MJ, Schleien CL, Kuluz JW, et al. 1995. Early endothelial damage and leukocyte accumulation in piglet brains following cardiac arrest. Acta Neuropathol, 90:582-91.

Chen M, Inestrosa NC, Ross GS, et al. 1995. Platelets are the primary source of amyloid- $\beta$ peptide in human blood. Biochem Biophys Res Commun, 213:96-103.

Chen J, Xu W, Jiang H. 2001. 17beta-estradiol protects neurons from ischemic damage and attenuates accumulation of extracellular excitatory amino acids. Anesth Analg, 92:1520-3.

Chi OZ, Liu X, Weiss HR. 2002. Effects of 17beta-estradiol on bloodbrain barrier disruption during focal ischemia in rats. Horm Metab Res, 34:530-4.

Chi OZ, Hunter C, Liu X, et al. 2005. Effects of 17beta-estradiol on bloodbrain barrier disruption in focal ischemia during GABA (A) receptor inhibition. Horm Metab Res, 37:209-13.

D'Andrea MR, Cole GM, Ard MD. 2004. The microglial phagocytic role with specific plaque types in the Alzheimer disease brain. Neurobiol Aging, 25:675-83.

D'Andrea MR. 2005. Add Alzheimer's disease to the list of autoimmune diseases. Med Hypotheses, 64:458-63.

Deane R, Du Yan S, Submamaryan RK, et al. 2003. RAGE mediates amyloid- $\beta$ peptide transport across the blood-brain barrier and accumulation in brain. Nat Med, 9:907-13.
Dede DS, Yavuz B, Yavuz BB, et al. 2007. Assessment of endothelial function in Alzheimer's disease: is Alzheimer's disease a vascular disease? J Am Geriatr Soc, 55:1613-7.

Dickstein DL, Biron KE, Ujiie M, et al. 2006. A $\beta$ peptide immunization restores blood-brain barrier integrity in Alzheimer disease. FASEB $J$, 20:426-33.

Dubal DB, Kashon ML, Pettigrew LC, et al. 1998. Estradiol protects against ischemic injury. J Cereb Blood Flow Metab, 18:1253-8.

Erusalimsky JD, Kurz DJ. 2005. Cellular senescence in vivo: its relevance in aging and cardiovascular disease. Exp Gerontol, 40:634-42.

Farkas IG, Czigner A, Farkas E, et al. 2003. Beta-amyloid peptide-induced blood-brain barrier disruption facilitates T-cell entry into the rat brain. Acta Histochem, 105:115-25.

Fiala M, Zhang L, Gan X, et al. 1998. Amyloid-beta induces chemokine secretion and monocyte migration across a human blood-brain barrier model. Mol Med, 4:480-9.

Gartshore G, Patterson J, Macrae IM. 1997. Influence of ischemia and reperfusion on the course of brain tissue swelling and blood-brain barrier permeability in a rodent model of transient focal cerebral ischemia. Exp Neurol, 147:353-60.

Gidday JM, Gasche YG, Copin JC, et al. 2005. Leukocyte-derived matrix metalloproteinase-9 mediates blood-brain barrier breakdown and is proinflammatory after transient focal cerebral ischemia. Am J Physiol Heart Circ Physiol, 289:H558-68.

Grammas P. 2000. A damaged microcirculation contributes to neuronal cell death in Alzheimer's disease. Neurobiol Aging, 21:199-205.

Humpel C, Marksteiner J. 2005. Cerebrovascular damage as a cause for Alzheimer's disease. Curr Neurovasc Res, 2:341-7.

Ishikawa M, Cooper D, Arumugam TV, et al. 2004. Platelet-leukocyteendothelial cell interactions after middle cerebral artery occlusion and reperfusion. J Cereb Blood Flow Metab, 24:907-15.

Ishimaru H, Ishikawa K, Haga S, et al. 1996. Accumulation of apolipoprotein $\mathrm{E}$ and $\beta$-amyloid-like protein in a trace of the hippocampal CA1 pyramidal cell layer after ischaemic delayed neuronal death. NeuroReport, 7:3063-7.

Iwasaki K, Egashira N, Hatip-Al-Khatib I, et al. 2006. Cerebral ischemia combined with beta-amyloid impairs spatial memory in the eight-arm radial maze task in rats. Brain Res, 1097:216-23.

Jendroska K, Poewe W, Daniel SE, et al. 1995. Ischemic stress induces deposition of amyloid beta immunoreactivity in human brain. Acta Neuropathol, 90:461-6.

Kalaria RN. 1999. The blood-brain barrier and cerebrovascular pathology in Alzheimer's disease. Ann NY Acad Sci, 893:113-25.

Kalaria RN. 2000. The role of cerebral ischemia in Alzheimer's disease. Neurobiol Aging, 21:321-30.

Kalaria RN. 2002. Small vessel disease and Alzheimer's dementia: Pathological considerations. Cerebrovasc Dis, 13(Suppl 2):48-52.

Kang HS, Ahn HS, Kang HJ, et al. 2006. Effect of estrogen on the expression of occludin in ovariectomized mouse brain. Neurosci Lett, 402:30-4.

Kawai M, Kalaria RN, Harik SI, et al. 1990. The relationship of amyloid plaques to cerebral capillaries in Alzheimer's disease. Am J Pathol, 137:1435-46.

Kida E, Pluta R, Lossinsky AS, et al. 1995. Complete cerebral ischemia with short-term survival in rat induced by cardiac arrest. II. Extracellular and intracellular accumulation of apolipoproteins $\mathrm{E}$ and $\mathrm{J}$ in the brain. Brain Res, 674:341-6.

Koistinaho M, Kettunen MI, Goldsteins G, et al. 2002. Beta-amyloid precursor protein transgenic mice that harbor diffuse A beta deposits but do not form plaques show increased ischemic vulnerability: role of inflammation. Proc Natl Acad Sci U S A, 99:1610-5.

Koistinaho M, Lin S, Wu X, et al. 2004. Apolipoprotein E promotes astrocyte colocalization and degradation of deposited amyloid- $\beta$ peptides. Nat Med, 10:719-26.

Lippoldt A, Kniesel U, Liebner, S, et al. 2000. Structural alterations of tight junctions are associated with loss of polarity in stroke-prone spontaneously hypertensive rat blood-brain barrier endothelial cells. Brain Res, 885:251-61. 
Lupo G, Anfuso CD, Assero G, et al. 2001. Amyloid $\beta$ (1-42) and its $\beta$ (25-35) fragment induce in vitro phosphatidylcholine hydrolysis in bovine retina capillary pericytes. Neurosci Lett, 303:185-8.

Malm TM, Koistinaho M, Parepalo M, et al. 2005. Bone-marrow-derived cells contribute to the recruitment of microglial cells in response to beta-amyloid deposition in APP/PS1 double transgenic Alzheimer mice. Neurobiol Dis, 18:134-42.

Matsunaga W, Shirokawa T, Isobe K. 2003. Specific uptake of Abeta 1-40 in rat brain occurs in astrocyte, but not in microglia. Neurosci Lett, 342:129-31.

McCullough LD, Alkayed NJ, Traystman RJ, et al. 2001 Postischemic estrogen reduces hypoperfusion and secondary ischemia after experimental stroke. Stroke, 32:796-802.

Mehta PD, Pirttila T. 2002. Biological markers of Alzheimer's disease. Drug Dev Res, 56:74-84.

Minamino T, Miyauchi H, Yoshida T, et al. 2004. Vascular cell senescence and vascular aging. J Mol Cell Cardiol, 36:175-83.

Mossakowski MJ, Lossinsky AS, Pluta R, et al. 1993. Changes in cerebral microcirculation system following experimentally induced cardiac arrest: a SEM and TEM study. In: Tomita M (ed). Microcirculatory stasis in the brain. Amsterdam: Elsevier Science Publishers BV, pp. 99-106.

Mossakowski MJ, Lossinsky AS, Pluta R, et al. 1994. Abnormalities of the blood-brain barrier in global cerebral ischemia in rats due to experimental cardiac arrest. Acta Neurochir Suppl (Wien), 60:274-6.

Nimmo AJ, Cernak I, Heath DL, et al. 2004. Neurogenic inflammation is associated with development of edema and functional deficits following traumatic brain injury in rats. Neuropeptides, 38:40-7.

Nishijima K, Kiryu J, Tsujikawa A, et al. 2004. Platelets adhering to the vascular wall mediate postischemic leukocyte-endothelial cell interactions in retinal microcirculation. Invest Ophthalmol Vis Sci, 45:977-84.

Niwa K, Younkin L, Ebeling C, et al. 2000. Abeta 1-40-related reduction in functional hyperemia in mouse neocortex during somatosensory activation. Proc Natl Acad Sci U S A, 97:9735-40.

Ohtake M, Morino S, Kaidoh T, et al. 2004. Three-dimensional structural changes in cerebral microvessels after transient focal cerebral ischemia in rats: Scanning electron microscopic study of corrosion casts. Neuropathology, 24:219-27.

Palacios G, Mengod G, Tortosa A, et al. 1995. Increased $\beta$-amyloid precursor protein expression in astrocytes in the gerbil hippocampus following ischaemia: Association with proliferation of astrocytes. Eur J Neurosci, 7:501-10.

Paris D, Patel N, DelleDonne A, et al. 2004a. Impaired angiogenesis in a transgenic mouse model of cerebral amyloidosis. Neurosci Lett, $366: 80-5$.

Paris D, Townsend K, Quadros A, et al. 2004b. Inhibition of angiogenesis by A $\beta$ peptides. Angiogenesis, 7:75-85.

Pennypacker KR, Hernandez H, Benkovic S, et al. 1999. Induction of presenilins in the rat brain after middle cerebral arterial occlusion. Brain Res Bull, 48:539-43.

Petito CK, Pulsinelli WA, Jacobson G, et al. 1982. Edema and vascular permeability in cerebral ischemia: comparison between ischemic neuronal damage and infarction. J Neuropathol Exp Neurol, 41:423-36.

Pluta R, Lossinsky AS, Mossakowski MJ, et al. 1991. Reassessment of new model of complete cerebral ischemia in rats. Method of induction of clinical death, pathophysiology and cerebrovascular pathology. Acta Neuropathol, 83:1-11.

Pluta R, Lossinsky AS, Wisniewski HM, et al. 1994a. Early blood-brain barrier changes in the rat following transient complete cerebral ischemia induced by cardiac arrest. Brain Res, 633:41-52.

Pluta R, Kida E, Lossinsky AS, et al. 1994b. Complete cerebral ischemia with short-term survival in rats induced by cardiac arrest. I. Extracellular accumulation of Alzheimer's $\beta$-amyloid protein precursor in the brain. Brain Res, 649:323-8.

Pluta R, Lossinsky AS, Walski M, et al. 1994c. Platelet occlusion phenomenon after short- and long-term survival following complete cerebral ischemia in rats produced by cardiac arrest. J Brain Res, 35:463-71.
Pluta R, Barcikowska M, Januszewski S, et al. 1996. Evidence of blood-brain barrier permeability/leakage for circulating human Alzheimer's $\beta$-amyloid- (1-42)-peptide. NeuroReport, 7:1261-5.

Pluta R, Misicka A, Januszewski S, et al. 1997a. Transport of human $\beta$-amyloid peptide through the rat blood-brain barrier after global cerebral ischemia. Acta Neurochir Suppl, 70:247-9.

Pluta R, Barcikowska M, Kida E, et al. 1997b. Late extracellular deposits of $\beta$-amyloid precursor protein in ischaemic rat brain show different immunoreactivity to the $\mathrm{N}$ - and C-terminal. Alzheimer's Res, 3:51-7.

Pluta R, Barcikowska M, Misicka A, et al. 1999. Ischemic rats as a model in the study of the neurobiological role of human $\beta$-amyloid peptide. Time-dependent disappearing diffuse amyloid plaques in brain. NeuroReport, 10:3615-9.

Pluta R. 2000. The role of apolipoprotein E in the deposition of $\beta$-amyloid peptide during ischemia-reperfusion brain injury. A model of early Alzheimer's disease. Ann NY Acad Sci, 903:324-34.

Pluta R, Misicka A, Barcikowska M, et al. 2000. Possible reverse transport of $\beta$-amyloid peptide across the blood-brain barrier. Acta Neurochir Suppl, 76:73-7.

Pluta R. 2001. Proteins associated with Alzheimer's disease in conditions predisposing to Alzheimer's-type neurodegeneration. J Cereb Blood Flow Metab, 21(Suppl 1):S424.

Pluta R. 2002a. Glial expression of the beta-amyloid peptide in cardiac arrest. J Neurol Sci, 203-204:277-80.

Pluta R. 2002b. Astroglial expression of the beta-amyloid in ischemiareperfusion brain injury. Ann NY Acad Sci, 977:102-8.

Pluta R. 2003. Blood-brain barrier dysfunction and amyloid precursor protein accumulation in microvascular compartment following ischemiareperfusion brain injury with 1-year survival. Acta Neurochir Suppl, $86: 117-22$.

Pluta R. 2004a. Alzheimer lesions after ischemia-reperfusion brain injury. Folia Neuropathol, 42:181-6.

Pluta R. 2004b. From brain ischemia-reperfusion injury to possible sporadic Alzheimer's disease. Curr Neurovasc Res, 1:441-53.

Pluta R. 2005. Pathological opening of the blood-brain barrier to horseradish peroxidase and amyloid precursor protein following ischemiareperfusion brain injury. Chemotherapy, 51:223-6.

Pluta R. 2006a. Ischemia-reperfusion factors in sporadic Alzheimer's disease. In: Welsh EM (ed). New research on Alzheimer's disease. New York: Nova Science Publishers, pp. 183-234.

Pluta R. 2006b. Is the ischemic blood-brain barrier insufficiency responsible for full-blown Alzheimer's disease? Neurol Res, 28:266-71.

Pluta R, Ułamek M, Januszewski S. 2006. Micro-blood-brain barrier openings and cytotoxic fragments of amyloid precursor protein accumulation in white matter after ischemic brain injury in long-lived rats. Acta Neurochir Suppl, 96:267-71.

Pluta R. 2007a. Role of ischemic blood-brain barrier on amyloid plaques development in Alzheimer's disease brain. Curr Neurovasc Res, 4:121-9.

Pluta R. 2007b. Is the ischemic blood-brain barrier a Trojan horse in Alzheimer's disease brain? In: Pluta R (ed). Ischemia-reperfusion pathways in Alzheimer's disease. New York: Nova Science Publishers, Inc., pp. 139-84.

Pluta R. 2007c. Ischemia-reperfusion pathways in Alzheimer's disease. New York: Nova Science Publishers, Inc.

Ramsauer M, Krause D, Dermietzel R. 2002. Angiogenesis of the bloodbrain barrier in vitro and the function of cerebral pericytes. FASEB J, 16:1274-6.

Ritter LS, Stempel KM, Coull BM, et al. 2005. Leukocyte-platelet aggregates in rat peripheral blood after ischemic stroke and reperfusion. Biol Res Nurs, 6:281-8.

Sadowski M, Wisniewski HM, Jakubowska-Sadowska K, et al. 1999. Pattern of neuronal loss in the rat hippocampus following experimental cardiac arrest-induced ischemia. J Neurol Sci, 168:13-20.

Shi J, Panickar KS, Yang SH, et al. 1998. Estrogen attenuates overexpression of beta-amyloid precursor protein messenger RNA in an animal model of focal ischemia. Brain Res, 810:87-92. 
Shinnou M, Ueno M, Sakamoto H, et al. 1998. Blood-brain barrier damage in reperfusion following ischemia in the hippocampus of the Mongolian gerbil brain. Acta Neurol Scand, 98:406-11.

Simard AR, Soulet D, Gowing G, et al. 2006. Bone marrow-derived microglia play a critical role in restricting senile plaque formation in Alzheimer's disease. Neuron, 49:489-502.

Simpkins JW, Rajakumar G, Zhang YQ, et al. 1997. Estrogens may reduce mortality and ischemic damage caused by middle cerebral artery occlusion in the female rat. J Neurosurg, 87:724-30.

Sohrabji F. 2007. Guarding the blood-brain barrier: A role for estrogen in the etiology of neurodegenerative disease. Gene Expression, 13:311-9.

Spires TL, Hyman BT. 2005. Transgenic models of Alzheimer's disease: learning from animals. NeuroRx, 2:423-37.

Stoltzner SE, Grenfell TJ, Mori C, et al. 2000. Temporal accrual of complement proteins in amyloid plaques in Down's syndrome with Alzheimer's disease. Am J Pathol, 156:489-99.

Sun X, He G, Qing H, et al. 2006. Hypoxia facilitates Alzheimer's disease pathogenesis by up-regulating BACE1 gene expression. Proc Natl Acad Sci US A, 103:18727-32.

Swerdlow RH. 2007. Is aging part of Alzheimer's disease, or is Alzheimer's disease part of aging. Neurobiol Aging, 28:1465-80.

Takuma K, Baba A, Matsuda T. 2004. Astrocyte apoptosis: Implications for neuroprotection. Prog Neurobiol, 72:111-27.

Tanimukai H, Imaizumi K, Kudo T, et al. 1998. Alzheimer-associated presenilin-1 gene is induced in gerbil hippocampus after transient ischemia. Mol Brain Res, 54:212-8.

Thomas T, Thomas G, McLendon C, et al. 1996. $\beta$-amyloid-mediated vasoactivity and vascular endothelial damage. Nature, 380:168-71.

Ueno M, Tomimoto H, Akiguchi I, et al. 2002. Blood-brain barrier disruption in white matter lesions in a rat model of chronic cerebral hypoperfusion. J Cereb Blood Flow Metab, 22:97-104.
Ujiie M, Dickstein DL, Carlow DA, et al. 2003. Blood-brain barrier permeability precedes senile plaque formation in an Alzheimer disease model. Microcirculation, 10:463-70.

Van Groen T, Puurunen K, Maki HM, et al. 2005. Transformation of diffuse beta-amyloid precursor protein and beta-amyloid deposits to plaques in the thalamus after transient occlusion of the middle cerebral artery in rats. Stroke, 36:1551-6.

Wen Y, Onyewuchi O, Yang S, et al. 2004. Increased beta-secretase activity and expression in rats following transient cerebral ischemia. Brain Res, 1009:1-8.

Wisniewski HM, Pluta R, Lossinsky AS, et al. 1995. Ultrastructural studies of cerebral vascular spasm after cardiac arrest-related global cerebral ischemia in rats. Acta Neuropathol, 90:432-40.

Wisniewski HM, Maslinska D. 1996. Beta-protein immunoreactivity in the human brain after cardiac arrest. Folia Neuropathol, 34:65-71.

Wolfe MS, Xia W, Ostaszewski BL, et al. 1999. Two transmembrane aspartates in presenilin-1 required for presenilin endoproteolysis and gamma-secretase activity. Nature, 398:513-7.

Wyss-Coray T, Loike JD, Brionne TC, et al. 2003. Adult mouse astrocytes degrade amyloid-beta in vitro and in situ. Nat Med, 9:453-7.

Yang SH, Liu R, Perez EJ, et al. 2005. Estrogens as protectants of the neurovascular unit against ischemic stroke. Curr Drug Targets CNS Neurol Disord, 4:169-77.

Zhang X, Zhou K, Wang R, et al. 2007. Hypoxia-inducible factor $1 \alpha(\mathrm{HIF}-1 \alpha)$-mediated hypoxia increases BACE1 expression and $\beta$-amyloid generation. J Biol Chem, 282:10873-80.

Zipser BD, Johanson CE, Gonzalez L, et al. 2007. Microvascular injury and blood-brain barrier leakage in Alzheimer's disease. Neurobiol Aging, 27:977-86. 